\title{
Performance Test Results of Noninvasive Characterization of RCRA Surrogate Waste by Prompt Gamma Neutron Activation Analysis
}

\author{
RESEEIVED \\ JUL O 1998 \\ OSTI
}

R. J. Gehrke

W. A. Propp

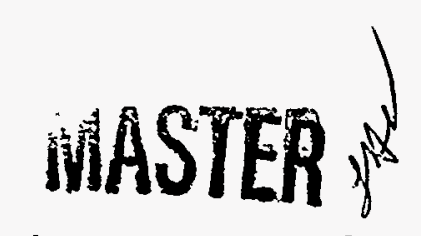

DISTRIBUTION OF THIS COOUNENT IS UNLIMITED 


\section{DISCLAIMER}

This report was prepared as an account of work sponsored by an agency of the United States Government. Neither the United States Government nor any agency thereof, nor any of their employees, makes any warranty, express or implied, or assumes any legal liability or responsibility for the accuracy, completeness, or usefulness of any information, apparatus, product or process disclosed, or represents that its use would not infringe privately owned rights. References herein to any apecific commercial product, process, or service by trade name, trademark, manufacturer, or otherwive, does not necessarily constitute or imply its endorsement, recommendation, or favoring by the United States Government or any agency thereof. The views and opinions of authors expressed herein do not necessarily state or reflect those of the United States Goyernment or any agency thereof. 


\section{DISCLAIMER}

Portions of this document may be illegible in electronic image products. Images are produced from the best available original document. 


\title{
Performance Test Results of Noninvasive Characterization of RCRA Surrogate Waste by Prompt Gamma Neutron Activation Analysis
}

\author{
R. J. Gehrke and W. A. Propp
}

Published November 1997

\section{Idaho National Engineering and Environmental Laboratory Mixed Waste Focus Area Department Lockheed Martin Idaho Technologies Company Idaho Falls, Idaho 83415}

\author{
Prepared for the \\ U.S. Department of Energy \\ Assistant Secretary for Environmental Management \\ Under DOE Idaho Operations Office \\ Contract DE-AC07-94ID13223
}




\begin{abstract}
A performance evaluation to determine the feasibility of using prompt gamma neutron activation analysis (PGNAA) for noninvasive, quantitative assay of mixed waste containers was sponsored by DOE's Office of Technology Development (OTD), the Mixed Waste Focus Area (MWFA), and the Idaho National Engineering and Environmental Laboratory (INEEL). The evaluation was conducted using a surrogate waste, based on Portland cement, that was spiked with three RCRA metals, mercury, cadmium, and lead. The results indicate that PGNAA has potential as a process monitor. However, further development is required to improve its sensitivity to meet regulatory requirements for determination of these RCRA metals.
\end{abstract}




\section{CONTENTS}

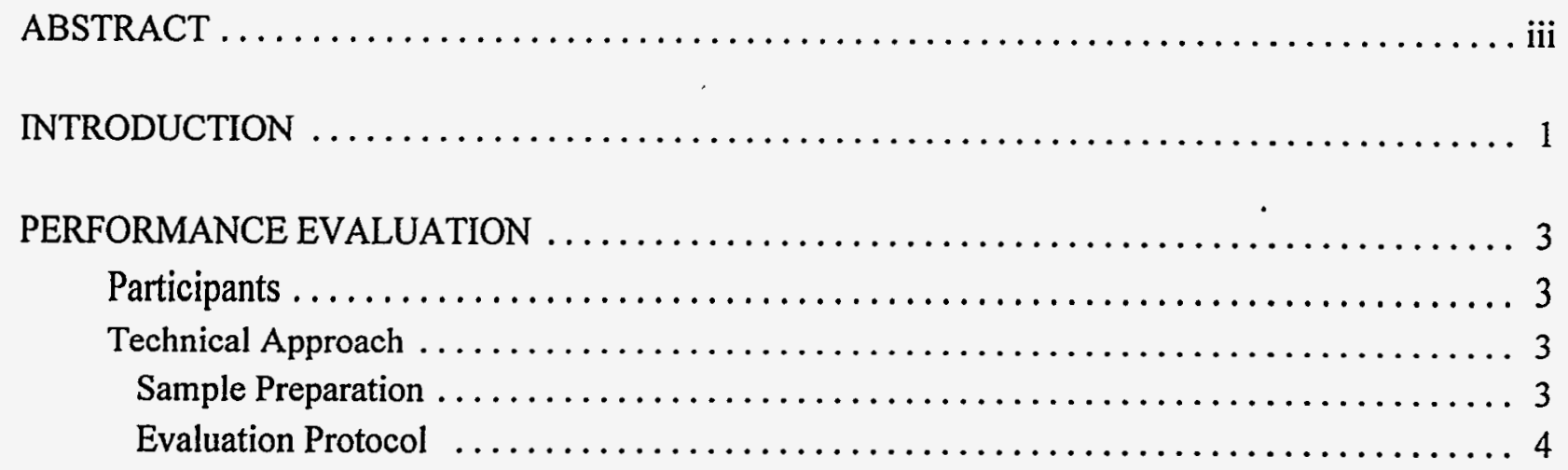

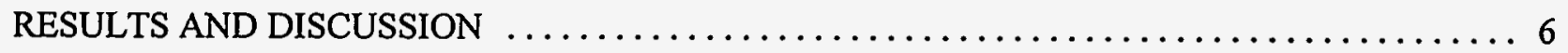

Results for WSTC Nuclear Laboratory (WSTCNL) $\ldots \ldots \ldots \ldots \ldots \ldots \ldots \ldots \ldots \ldots$

Bechtel Nevada Special Technologies Laboratory (STL) $\ldots \ldots \ldots \ldots \ldots \ldots \ldots \ldots \ldots$

CONCLUSIONS AND RECOMMENDATIONS $\ldots \ldots \ldots \ldots \ldots \ldots \ldots \ldots \ldots \ldots \ldots$

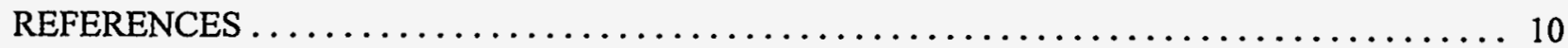

\section{Tables}

1. Heavy metal concentrations of simulated waste drums. . . . . . . . . . . . . . . . 4

2. Comparison of measured and actual concentrations from repeat calibration runs. ........6 6

3. Results reported by WSTCNL for blind surrogate waste drums. $\ldots \ldots \ldots \ldots \ldots \ldots \ldots \ldots \ldots$

4. Variance between results reported by WSTCNL for blind surrogate waste drums and the actual

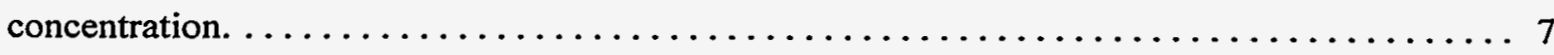

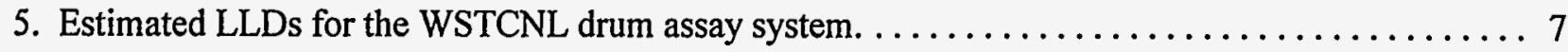




\section{PERFORMANCE TEST RESULTS OF NONINVASIVE CHARACTERIZATION OF RCRA SURROGATE WASTE BY PROMPT GAMMA NEUTRON ACTIVATION ANALYSIS}

\section{INTRODUCTION}

The U.S. Department of Energy (DOE) has accumulated a sizable quantity of mixed, transuranic (TRU) waste as a result of 40 years of nuclear weapons production. An appreciable fraction of this waste resides at the Idaho National Engineering and Environmental Laboratory (INEEL). Much of this waste is stored above ground under conditions that will allow its retrieval for reprocessing, if required, and ultimate disposal in a permanent repository, such as the Waste Isolation Pilot Plant (WIPP). Current estimates are that there are more than 135,000 55-gal drums of mixed TRU waste at the INEEL alone and that about $55 \%$ of this waste is sludge that will require stabilization or solidification prior to disposal.

The hazardous constituents of this mixed waste include heavy metals, such as mercury, cadmium, and lead, that are regulated under the Resource Conservation and Recovery Act (RCRA) (40 CFR 264, Subpart B). This Act requires that treatment/disposal facilities conduct sufficient analyses of any waste proposed for treatment/disposal to verify that the physical and chemical properties of the waste fall within the operating permit for the facility. Furthermore, the waste stream characterization is used to establish limits on operational parameters so that any emissions are within the facility operating permits.

Because of the lack of effective alternatives, most waste analyses are currently performed using grab samples. However, there are several significant disadvantages in applying this type of sampling to the INEEL waste drums, including the following.

- Sample collection requires opening many waste containers;

- Sample collection and analysis are expensive and time-consuming;

- Real-time waste characterization information cannot be obtained;

- Waste inhomogeneity complicates characterization and presents the risk of nonrepresentative information;

- Personnel exposure to, and environmental release of, radioactive and hazardous constituents may occur during sampling and analysis.

To overcome these disadvantages, DOE has proposed to supplement or replace analysis of grab samples of DOE mixed wastes with on-stream, noninvasive, elemental assay for RCRA-identified heavy metals and other specific elements, such as carbon, chlorine, and sulfur. Noninvasive assay has several advantages over batch sampling and analysis, including reducing hazards by avoiding opening of sealed containers and direct handling of waste and the ability to determine either bulk averaged composition or spatially resolved composition. However, prior to this, no noninvasive method had been evaluated for 
measurement accuracy and sensitivity for assay of either actual or simulated wastes. The purpose of this project was to obtain such an evaluation.

A performance evaluation to determine the feasibility of using prompt gamma neutron activation analysis (PGNAA) for noninvasive, quantitative assay of mixed waste containers was sponsored by DOE's Office of Technology Development (OTD), the Mixed Waste Focus Area (MWFA), and the INEEL. The performance evaluation and its results are described in this report. 


\section{PERFORMANCE EVALUATION}

\section{Participants}

All commercial firms or national laboratories with experience in the use of PGNAA techniques and a system with which to conduct the evaluation assays were eligible to participate. Six respondents to a call for proposal in the Commerce Business Daily and to personal contacts were initially identified for further consideration. WSTC Nuclear Laboratory of Westinghouse Science \& Technology Center (WSTCNL) and Special Technologies Laboratory of Bechtel Nevada (STL) were ultimately selected to perform PGNAA evaluations.

\section{Technical Approach}

\section{Sample Preparation}

The evaluation assays were performed on a simulated sludge waste. Sludge was selected because

- A large fraction of DOE's TRU mixed waste is organic and inorganic sludges

- Sludges tend to be more homogeneous than other wastes, simplifying this initial evaluation of the PGNAA technique

- $\quad$ Sludges are high density matrices.

Successful assay of the simulated sludge implies that a significant portion of the waste volume could be assayed. Furthermore, if accurate and sensitive assays can be performed on this high density matrix, it is reasonable to assert that other high and low density matrices can be assayed with equal success. In particular, it would be expected that any low density matrix containing high-neutron cross-section elements could be characterized using this type of technique.

The major requirement in developing the simulated waste for this evaluation was that its final waste form pass the U.S. EPA toxicity characterization leaching test (TCLP) so that it would not be classified as toxic for disposal purposes. The simulated waste matrix developed was based upon Portland cement mixed with sand and sodium nitrate $\left[\mathrm{Na}(\mathrm{NO})_{3}\right]$, which was added because the majority of DOE wastes contain high levels of nitrate. Three heavy metals that are typically found in DOE wastes, cadmium $(\mathrm{Cd})$, lead $(\mathrm{Pb})$, and mercury $(\mathrm{Hg})$, were selected as the analytes for this performance evaluation. One of the reasons for their selection was that they have, respectively, high, low, and medium thermal neutron cross sections. The simulated waste was spiked with concentrations of each metal ranging from approximately 300 to $20,000 \mathrm{ppm}$. These metals were added as sulfides to prevent reactions with the waste matrix. To reduce the potential for cross interferences between the counting peaks, mercury was added to different batches than lead and cadmium. The low thermal neutron cross section of lead ( 0.180 barns) and the high cross section of cadmium (2,450 barns) are sufficiently separated to prevent significant interference if the inelastic scatter peaks of lead are analyzed; however, the medium thermal neutron cross section of mercury ( 375 barns) could potentially result in cross interference if it was present with the other two metals. 
Batches of simulated waste were mixed and poured into 8-gal steel drums lined with multiple layers of plastic trash bags. Each batch filled three drums, producing three identical sample drums. One drum from each batch was retained as part of an archived set, and one went to each of the two evaluation participants.

Fourteen batches of simulated sludge waste were prepared, one without any heavy metal (blank) and 13 spiked with various concentrations of cadmium, lead, and mercury as noted above. For calibration purposes, the heavy metal concentrations of the blank drum and seven of the spiked drums were provided to the participants. The remaining six drums were unknown samples for analysis. The heavy metal concentrations of all 14 drums are listed in Table 1.

\section{Evaluation Protocol}

The participants were to report their data in similar formats, so sample forms for reporting results were provided. The following protocol was to be used for instrument calibration and the blind analyses.

1. The instrument was calibrated. (The method of calibration was not specified but was to be reported.)

2. One of the drums used to establish the initial calibration was recounted to verify that the predicted elemental concentrations were within the predicted uncertainty

3. Each of the blind drums was assayed twice; the drum was removed and replaced in the counting position between assays

4. Two counting times were used for each assay, $600 \mathrm{~s}$ and $2,000 \mathrm{~s}$ real time

5. The uncertainty component due to nonreproducibility in the experimental geometry was demonstrated through sequential assays of one of the drums to vary by not more than $5 \%$

Table 1. Heavy metal concentrations of simulated waste drums.

\begin{tabular}{ccccc}
\hline & & \multicolumn{3}{c}{ Concentration (ppm) } \\
\cline { 3 - 5 } Drum No. & Description & Mercury & Cadmium & Lead \\
\hline 1 & Blank & 0 & 0 & 0 \\
2 & Blind & 18110 & 0 & 0 \\
3 & Blind & 5835 & 0 & 0 \\
4 & Blind & 583 & 0 & 0 \\
5 & Blind & 0 & 4970 & 18080 \\
6 & Blind & 0 & 808 & 8844 \\
7 & Blind & 0 & 291 & 0 \\
8 & Hg calibration & 19820 & 0 & 0 \\
9 & Hg calibration & 8177 & 0 & 0 \\
10 & Hg calibration & 1942 & 0 & 0 \\
11 & Hg calibration & 487 & 0 & 0 \\
12 & Cd/Pb calibration & 0 & 8181 & 19950 \\
13 & Cd/Pb calibration & 0 & 2123 & 9927 \\
14 & Cd calibration & 0 & 485 & 0 \\
& & & & \\
\hline
\end{tabular}


6. The blank drum was counted and the data used to subtract background interference peaks; the background peaks and the elements associated with them were identified on the participant reporting form.

The elemental concentration of each analyte in each blind drum was to be determined and reported in accordance with the following requirements.

1. For an elemental concentration to be considered detected, the primary signal for a given elemental assay had an estimated standard deviation of less than $35 \%$ for the combined uncertainty in the counting statistics and peak fitting uncertainty, which would be equivalent to a lower limit of detection (LLD) as defined by L. A. Currie ${ }^{1}$

2. For an elemental concentration to be considered quantified, the primary signal from a blind surrogate sample had an estimated standard deviation of less than $20 \%$ for the counting uncertainty component, and the total uncertainty for a quantified measurement was less than $25 \%$ with the estimated standard deviations for the components combined in the normal manner

3. The LLD was to be estimated by the procedure proposed by Currie. ${ }^{1}$

The goal of the analysis was to detect each of the three heavy metal analytes in a $600 \mathrm{~s}$ counting period at the lowest concentration in a blind sample with an estimated uncertainty, i.e. one standard deviation for the counting statistics, of less than $35 \%$. The PGNAA system performance was evaluated based on the lowest concentration of each metal that could be detected and quantified.

The information reported by each of the participants for the blind simulated waste was scored using the following criteria.

\section{Criterion}

Each element correctly identified as present

Each quantitative assay

Correct within $10 \%$ of the actual concentration

Correct within $20 \%$ of the actual concentration

Differing from the actual concentration by 20 to $50 \%$

Each incorrect quantitative assay of an element present that differed from the actual concentration by more than $50 \%$
Points

10 , weighted by the cube root of the percent concentration

5 , weighted by the cube root of the percent concentration

-10 , weighted by the cube root of the percent concentration

Deviations from the "Instructions to the Participants" without written permission of the evaluation coordinator could result in a reduction in points or disqualification of the participant from the performance evaluation. All results were to be submitted within six weeks of the participant's receipt of the samples. Based upon these criteria, a perfect score in the performance evaluation was 184.9 points. 


\section{RESULTS AND DISCUSSION}

This section gives the results of the performance evaluation; the data submitted by the participants are reported elsewhere. ${ }^{2}$

\section{Results for WSTC Nuclear Laboratory (WSTCNL)}

Following calibration, a calibration drum for each analyte metal was recounted to measure system reproducibility. WSTCNL obtained good agreement (Table 2) between the measured and actual concentrations for each of the analyte metals. For both mercury and cadmium, the reproducibility in the counting statistics was very good; the higher uncertainty in counting for lead can be attributed to the low cross section of that element. The overall uncertainty in the measurements includes geometric uncertainty factors. From the replicate measurements on the blind drums, WSTCNL estimated the maximum value of the uncertainty due to nonreproducibility in system geometry to be $4.8 \%$.

The WSTCNL results for the analyses of the blind simulated waste drums are presented in Table 3. The variance between the actual values and those reported by WSTCNL are shown in Table 4 . All of the variances are well within the range of those anticipated for measurements of this type.

WSTCNL used the results obtained from the lowest concentration calibration drums to estimate an LLD for each of the analyte metals using the current instrument configuration (Table 5).

WSTCNL scored of 142.1 out of the possible 184.9 points, the highest score on this performance test. They correctly identified the metals present in all of the blind samples and reported no false positives. They quantified each of the metals to within $\pm 20 \%$, except for cadmium in Drum 5 . WSTCNL participated in the evaluation during the summer of 1996 and met the requirement for completing the measurements within six weeks.

Table 2. Comparison of measured and actual concentrations from repeat calibration runs.

\begin{tabular}{|c|c|c|c|c|}
\hline & Element & $\begin{array}{c}\text { Actual } \\
\text { Concentration } \\
\text { (ppm) }\end{array}$ & $\begin{array}{c}\text { Measured } \\
\text { Concentration } \\
(\mathrm{ppm}) \\
\end{array}$ & $\begin{array}{c}\text { Variance }^{\mathrm{b}} \\
(\%)\end{array}$ \\
\hline & $\mathrm{Hg}$ & 19,820 & $21,360 \pm 4.5 \%$ & 7.8 \\
\hline & $\mathrm{Cd}$ & 485 & $520 \pm 5.1 \%$ & 7.2 \\
\hline & $\mathrm{Pb}$ & 19,950 & $18,814 \pm 16.0 \%$ & -5.7 \\
\hline & \multicolumn{4}{|c|}{ Listed uncertainty is the standard deviation due to counting error only. } \\
\hline b. & \multicolumn{4}{|c|}{ Variance $(\%)=100$ (Measured concentration - Actual concentration $) \div$ Actual concentration } \\
\hline
\end{tabular}


Table 3. Results reported by WSTCNL for blind surrogate waste drums.

\begin{tabular}{|c|c|c|c|}
\hline \multirow[b]{2}{*}{ Drum No. } & \multicolumn{3}{|c|}{ Concentration (ppm) } \\
\hline & Mercury & Cadmium & Lead \\
\hline 2 & $18,191 \pm 14.3 \%$ & $\mathrm{ND}^{\mathrm{a}}$ & ND \\
\hline 3 & $7,0321 \pm 14.1 \%$ & $\mathrm{ND}$ & ND \\
\hline 4 & $691 \pm 14.6 \%$ & ND & ND \\
\hline 5 & ND & $3,613 \pm 10.6 \%$ & $18,814 \pm 19.3 \%$ \\
\hline 6 & ND & $821 \pm 10.2 \%$ & $10,416 \pm 21.0 \%$ \\
\hline 7 & ND & $321 \pm 10.5 \%$ & ND \\
\hline \multicolumn{4}{|c|}{ ND $=$ Not detected. } \\
\hline
\end{tabular}

Table 4. Variance between results reported by WSTCNL for blind surrogate waste drums and the actual concentration.

\begin{tabular}{cccc}
\hline \multirow{2}{*}{$\begin{array}{c}\text { Drum } \\
\text { No. }\end{array}$} & Mercury & Variance (\%) & \\
\cline { 2 - 4 } 2 & 0.45 & Cadmium & Lead \\
3 & 20.5 & $\mathrm{NA}$ & $\mathrm{NA}$ \\
4 & 18.5 & $\mathrm{NA}$ & $\mathrm{NA}$ \\
5 & $\mathrm{NA}$ & -27.3 & $\mathrm{NA}$ \\
6 & $\mathrm{NA}$ & 1.6 & 4.1 \\
7 & $\mathrm{NA}$ & 10.3 & 17.8 \\
$\mathrm{n}$ & $\mathrm{N} A=$ Not applicable. & & $\mathrm{NA}$ \\
\multicolumn{2}{l}{ Variance $(\%)=100$ (Reported concentration - Actual concentration $) \div$ Actual concentration. }
\end{tabular}

Table 5. Estimated LLDs for the WSTCNL drum assay system.

\begin{tabular}{ccc}
\hline Element & Run Time (s) & LLD (ppm) \\
\hline \multirow{3}{*}{$\mathrm{Hg}$} & 2,000 & 115 \\
& 600 & 170 \\
$\mathrm{Cd}$ & 2,000 & 9 \\
& 600 & 15 \\
$\mathrm{~Pb}$ & 2,000 & 4,400 \\
& 600 & 8,600 \\
\hline
\end{tabular}




\section{Bechtel Nevada Special Technologies Laboratory (STL)}

STL found that the sulfide form of the metals significantly hampered their detection and identification with a sodium iodide detector. Sulfur has prompt gamma rays in the energy regions near several of the prompt gamma rays emitted from lead, cadmium, and mercury. Unfortunately, sulfides of lead, cadmium, and mercury are the optimum compounds for simulated waste due to their low leachability. STL did not attempt to determine mercury concentrations since the $14 \mathrm{MeV}$ associated particle imaging technique employed was primarily designed to image waste and detect the presence of bulk quantities of materials. The method was severely limited, in its present configuration, for quantitative assay of the selected heavy metals. Grading their results was difficult because no provision was made for incorrect identifications. Approximately half of the reported identifications were incorrect. Therefore, STL scored a total of 10 points out of a possible 184.9 points. 


\section{CONCLUSIONS AND RECOMMENDATIONS}

Based on the success of WSTCNL's implementation of PGNAA, it appears that the method has sufficient detection sensitivity to serve as a process monitor. However, since the RCRA limits for all three of the metals selected for this study, i.e., cadmium, lead, and mercury, is $1 \mathrm{ppm}$ or less and the LLD reported by WSTCNL for each metal is from approximately 1 to 4 orders of magnitude above this value, PGNAA does not appear to be useful in regulatory determination of RCRA constituents without further improvements in sensitivity. Nevertheless, these preliminary results for very simple wastes are supportive of more extensive evaluation of the method using surrogates of more complex waste and waste forms. 


\section{REFERENCES}

1. L. A. Currie, "Limits for Quantitative Detection and Quantitative Determination," Analytical Chemistry, 40, (1968), p. 586.

2. R. J. Gehrke and G. G. Streier, Performance Test Results of Noninvasive Characterization of Resource Conservation and Recovery Act Surrogate Waste by Prompt Gamma Neutron Activation Analysis, INEEL/EXT-97-00141, March 1997, 119 pp. 